Tropical Journal of Pharmaceutical Research June 2021; 20 (6): 1307-1319

ISSN: $1596-5996$ (print); 1596-9827 (electronic) (C) Pharmacotherapy Group, Faculty of Pharmacy, University of Benin, Benin City, 300001 Nigeria.

\title{
Awareness, perceptions and attitudes towards complementary and alternative medicine in Saudi Arabia: A cross-sectional and comparative study of students of healthcare professions
}

\author{
Aslam Khan ${ }^{1,2 *}$, Mohamed Eldigre Ahmed ${ }^{1,2}$, Ahmed Aldarmahi',2, Adnan Al \\ Shaikh $^{1,2}$, Zeeshan Feroz ${ }^{3,4}$, Dur-e-Shahwar Rehman ${ }^{3,4}$, Ismail Memon ${ }^{3,4}$, Ahmad \\ M Subahi ${ }^{1,2}$, Syed Faisal Zaidi ${ }^{2,5}$ \\ ${ }^{1}$ College of Science and Health Professions, King Saud bin Abdulaziz University for Health Sciences, Jeddah, Saudi Arabia, \\ ${ }^{2}$ King Abdullah International Medical Research Center, Ministry of National Guard Health Affairs, Jeddah, Saudi Arabia, \\ ${ }^{3}$ College of Science and Health Professions, King Saud bin Abdulaziz University for Health Sciences, Riyadh, Saudi Arabia, \\ ${ }^{4}$ King Abdullah International Medical Research Center, Riyadh, Saudi Arabia, ${ }^{5}$ Department of 5Pharmacology, School of \\ Medicine, Batterjee Medical College for Health Sciences and Technology, Jeddah, Saudi Arabia
}

*For correspondence: Email: aslamkhan_mkd@yahoo.co.uk, khanasl@ksau-hs.edu.sa; Tel: +966 122245498 ext 45498

\begin{abstract}
Purpose: To investigate health professions student's awareness, attitude, and perception towards the complementary and alternative medicine (CAM) and also to determine the influence of sociodemographic variables on the descriptive outcomes of this study.

Methods: A descriptive, cross-sectional, comparative study was conducted among Undergraduate Health Professions Students $(n=398)$ at King Saud bin Abdulaziz University for Health Sciences at Riyadh campus, through a validated questionnaire.

Results: The results of the study revealed that among various modalities of CAM, most students were aware and used prayers/spirituality, followed by nutritional supplements, cupping, massage, herbal medicine and yoga. The least effective modality was aromatherapy, whereas the most harmful modality was acupuncture. The data showed that the students obtained more information from friends/relatives and media and less from formal CAM training/courses. Awareness/self-use and beliefs/attitudes were found to have significant associations $(p<0.05)$ in regard to gender, parent's educational level, and family income.

Conclusion: The study shows that most of the healthcare students are aware of and demonstrate positive attitudes towards the effectiveness and safety of most CAM modalities. However, the lack of formal training or courses is a major barrier towards its use and practice.
\end{abstract}

Keywords: Cross-sectional study, Complementary and alternative medicine, Health professions students, Aromatherapy, Prayers/spirituality, Attitude

\footnotetext{
This is an Open Access article that uses a fund-ing model which does not charge readers or their institutions for access and distributed under the terms of the Creative Commons Attribution License (http://creativecommons.org/licenses/by/4.0) and the Budapest Open Access Initiative (http://www.budapestopenaccessinitiative.org/read), which permit unrestricted use, distribution, and reproduction in any medium, provided the original work is properly credited.

Tropical Journal of Pharmaceutical Research is indexed by Science Citation Index (SciSearch), Scopus, International Pharmaceutical Abstract, Chemical Abstracts, Embase, Index Copernicus, EBSCO, African Index Medicus, JournalSeek, Journal Citation Reports/Science Edition, Directory of Open Access Journals (DOAJ), African Journal Online, Bioline International, Open-J-Gate and Pharmacy Abstracts
} 


\section{INTRODUCTION}

Traditional medicine, also known as complementary and alternative medicine (CAM), has remained an alternative form of treatment. Coming under the umbrella of CAM, local beliefs, knowledge and treatments were used in various countries to prevent or cure several diseases. Complementary and alternative medicine is more effective in chronic diseases and deals mainly with products or procedures which are not usually considered as a part of allopathic/conventional medicine [1]. Traditional medicine involves diverse systems and the use of local herbs or herbal ingredients. Its practitioners follow the legacy of local experience when treating a disease.

In regard to the World Health Organization (WHO), "health is a not only the absence of disease but a state of complete physical, mental and social well-being" [2]. Not only does CAM cover physical health, but also has remedies for mental and social problems prevalent in society. In contrast, allopathic medicine mostly targets physical health. Recognizing the importance of $\mathrm{CAM}$, the National Institute of Health $(\mathrm{NIH})$ established the National Center for Complementary and Integrative Health (NCClH). $\mathrm{NCClH}$ is looking to combine both the complementary and the conventional methods which have evidence of safety and effectiveness. This health and wellness treatment method is growing all over the world. Experts are carefully examining the possible benefits of integrative health approaches in various health conditions, like symptoms relief in cancer patients and survivors, pain management, and programs for promoting healthy behaviors [3]. In recent times, a continuous and substantial increase in the use of CAM has been observed. People have showed interest and trust in CAM as an alternative option for relieving their health-related problems and reducing side effects emerged from conventional therapies [4].

Like in many countries around the world, the people in the Kingdom of Saudi Arabia believed in spiritual healing and herbal remedies. However, the Saudi government has not recognized CAM as an alternative remedy for relieving ailments until 1990 . In recent times, Saudis have showed more interest in CAM and gave their voices to it, accepting it as an alternative therapy. Therefore, trained experts started practicing complementary/alternative medicine [5]. The present state of using CAM in Saudi Arabia is not well documented. Nonetheless, some CAM practices have been seen around Saudi Arabia. In this study, we have evaluated the awareness, self-use, beliefs, and attitudes of health professions students towards CAM in Riyadh and compared these results with a similar study conducted in Jeddah [6].

\section{METHODS}

\section{Ethics approval}

This study was approved by the IRB (Institutional Review Board) of King Abdullah International Medical Research Center (study no. RJ19/091/J vide approval memo ref no. IRBC/1790/19. It was conducted following the international guidelines for human studies [7]. At the time of data collection, every participant gave their consent.

\section{Study design and sampling}

It is a cross-sectional study conducted during the period from December 2019 to May 2020 through a validated questionnaire. The target populations were the students of King Saud bin Abdulaziz University for Health Sciences (KSAUHS), Riyadh, Saudi Arabia, from the College of Medicine (COM), the College of Applied Medical Sciences (CAMS), the College of Pharmacy (COP), the College of Dentistry (COD), the College of Nursing (CON), and the College of Science and Health Professions (COSHP).

The questionnaires, along with written consent forms, were circulated to the participants. The consent form contained information related to the purpose and aim of the research, the contact information of the principal investigator, and the respondents' assurance of confidentiality. In the presence of one of the investigators/data collectors, the students were asked to fill out the questionnaire.

\section{Development of the study questionnaire}

The questionnaire, already validated and used in our previous study [6], was designed after an extensive literature review. The questionnaire consisted of 6 parts. The first part was related to the students' demographics, such as age, sex, college, and level/year at college. The second part investigated the awareness and self-use of various CAM modalities through yes/no questions. The third part asked about the perception of the effectiveness and harmfulness of CAM modalities through an ordinal question using a Likert Scale of 5 options; very effective/very harmful, effective/harmful, moderate, low and none, weighted 5, 4, 3, 2, and 1 respectively. The percentage of agreement was calculated by dividing the mean of the scale by the highest possible value (5). The fourth part 
was about the sources of information with yes/no option. The fifth part was about the observed barriers to CAM. The sixth (last) part sought information about the attitudes and beliefs towards CAM using an ordinal Likert scale of 5 options ranging from strongly disagree weighted (1) to strongly agree weighted (5). The questionnaire was bilingual; first it was written in English, then translated into Arabic to assist students who are unfamiliar with the English terms used for CAM modalities. The data were saved in a PC locked with a password allowing no one to access it without permission. No direct identification of the respondents was used in order to protect their privacy and confidentiality. Both hard and soft copies of research data were preserved in a secure unit within the NG-HA premises and only research team were able to access them.

\section{Sample size}

At the time of the study, the total number of students at COM, COD, COP, CON, CAMS, and COSHP were approximately 4145; 2410 were males, and 1735 were females. All students from all the colleges of the KSAU-HS, Riyadh campus, were eligible for inclusion in the study. Cochran equation was used to determine the total sample size ( $n=385)$, as in Eq 1 [8]. Data were collected as stratified random sampling where each college was taken as a stratum. Samples were collected based on each college's population proportion.

$n=\left[z^{2} \times P \times(1-P)\right] / d^{2}$

where $\mathrm{n}=$ the sample size, $\mathrm{P}=$ the anticipated population proportion of knowledge about CAM, $z=$ the standard variable of the normal distribution corresponding to $95 \%$ confidence level. $\mathrm{d}=$ the absolute statistical precision on either side of the anticipated population proportion. For example, if $\mathrm{P}=50 \%$ and $\mathrm{d}=$ 0.05 , then the initial sample size will be:

Sample size $(n)=1.96^{2} *(50 / 100) *(1-50 / 100) /$ $(0.05)^{2}=385$

\section{Statistical analysis}

SPSS statistics version 25 was used for the inferential and descriptive statistical analysis. Descriptive statistics included graphs, means and frequency tables. Inferential methods included chi-square test used to examine the association among the demographic data, the awareness and/or the use of CAM. At a significance level of $5 \%$, all hypotheses were tested.

\section{RESULTS}

418 questionnaires were circulated to the students; 398 out of which consented to participate in the study and completed the questionnaires and twenty of them did not take part in the study. The overall response rate was $95.2 \%$.

\section{Basic information}

Table 1 is a summary of the basic information about the students in the sample. Out of 398 students, $269(65.1 \%)$ were males and 139 $(34.9 \%)$ were females. The data were collected on the basis of the population size of the respective colleges; 123 students $(30.9 \%)$ were from COSHP, 118 (29.6 \%) from COM, 32 (8.0 $\%)$ from COP, 64 (16.1\%) from CAMS, 29 (7.3 $\%)$ from CON, and 32 (8.0\%) from COD. As a whole, $48.2 \%$ of the students were in their third educational year and about $40.7 \%$ were in the fourth year or above. Based on the parent's education level, results showed that $71.6 \%$ of the students' fathers and about $63.6 \%$ of the students' mothers had a university education level. $1.3 \%$ of the students' fathers and $42.5 \%$ of the students' mothers were unemployed. In addition, around $54.5 \%$ of the students' parents were earning more than SR 20,000 per month. The percentage of the students who had a family member in the health care sector was $46.5 \%$.

\section{Awareness, self-use, effectiveness, and harmfulness of CAM}

Figure 1 shows the overall level of awareness and self-use of CAM modalities among all participants. Awareness ranged from $26.9 \%$ for aromatherapy to $89.4 \%$ for prayers and spirituality. The percentages of the self-use of CAM modalities among the students were found to be lower when compared with the CAM awareness. The least used modality was aromatherapy $(4.3 \%)$ while the most-used modality was prayers and spirituality $(77.1 \%)$.

Figure 1 also shows the means and percentages of the students' agreement regarding their evaluation of the effectiveness of CAM modalities. The most effective modality was prayers/spirituality (81.5 \%), followed by nutritional supplements $(74.4 \%)$. The least effective CAM modality was aromatherapy (42.0 $\%)$. The students evaluated acupuncture as the most harmful modality $(56.3 \%)$, followed by herbal medicine (51.9\%). The least harmful modality was Prayers/ spirituality $(28.1 \%)$. 
Table 1: Basic demographic information of the study population

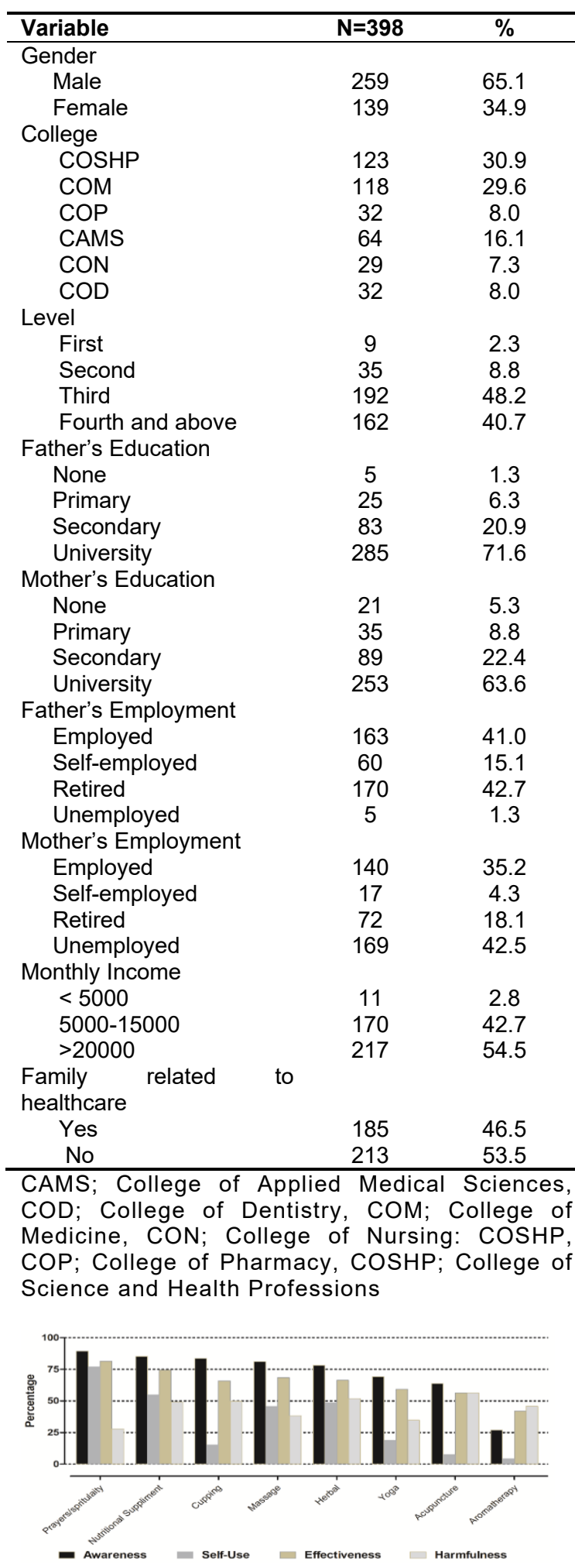

Figure 1: Student's awareness, and self- use, and perception of the effectiveness and harmfulness of CAM modalities

\section{Source of CAM Information}

Table 2 illustrates that $68.6 \%$ of the students indicated that relatives/friends were the main sources of CAM information. This was followed by the media (60.1\%). Similarly, books and media accounted for $54.3 \%$ and $60.1 \%$, respectively. However, formal CAM courses or training provided the students with the least information.

Table 2: Sources of information about CAM

\begin{tabular}{lcc}
\hline Source & Yes (\%) & No (\%) \\
\hline Books & 54.3 & 45.7 \\
Media & 60.1 & 39.9 \\
CAM practitioner & 54.8 & 45.2 \\
$\begin{array}{l}\text { Formal CAM } \\
\text { course or training }\end{array}$ & 33.7 & 66.3 \\
$\begin{array}{l}\text { Other health } \\
\text { professionals }\end{array}$ & 57.0 & 43.0 \\
$\begin{array}{l}\text { Friend } \\
\text { Relatives }\end{array}$ & 68.6 & 31.4 \\
\hline
\end{tabular}

\section{Apparent barriers to implementation of CAM}

Table 3 represents the students' perceptions about the barriers related to the use and implementation of CAM. $79-82 \%$ of the students concurred that the lack of trained professionals, scientific evidence, and knowledge about CAM were considered the main barriers to the implementation of CAM; however, the long time of treatment was considered to have the least impact on the implementation of CAM.

Table 3: Means and agreement percentages of perceived barriers to CAM implementation

\begin{tabular}{lcc}
\hline Statement & Scale mean & $\%$ \\
\hline $\begin{array}{l}\text { Lack of trained } \\
\text { professionals } \\
\text { Lack of scientific }\end{array}$ & 3.9 & 79.0 \\
evidence for & 3.9 & 78.8 \\
$\begin{array}{l}\text { Long time freatment } \\
\text { Lack of knowledge }\end{array}$ & 3.4 & 67.4 \\
about CAM & 4.0 & 80.2 \\
\hline
\end{tabular}

\section{Attitudes and beliefs of students regarding CAM}

The students' attitudes and beliefs towards CAM are summarized in Table 4, which represented the means of the Likert scale. Values higher than the medium (i.e 2.5 out of 5 ) represented a positive belief. The results of this study showed that more students had positive scores in all six questions. This reflected positive beliefs and attitudes towards CAM among the participants regardless of the gender and the colleges. 
However, the female students, in a significantly high number, responded positively to the following statement: "People are more likely to use CAM if their teachers discuss it with them".

Table 4: Means of values (out of 5 ) on beliefs and attitudes toward CAM

\begin{tabular}{|c|c|c|}
\hline Statement & Scale mean & $\%$ \\
\hline $\begin{array}{l}\text { CAM providers give } \\
\text { good information on } \\
\text { maintaining a healthy } \\
\text { lifestyle }\end{array}$ & 3.2 & 64.8 \\
\hline $\begin{array}{l}\text { CAM involves natural } \\
\text { plant formulas which are } \\
\text { healthier than taking } \\
\text { drugs given by the } \\
\text { medical doctor }\end{array}$ & 2.8 & 56.5 \\
\hline $\begin{array}{l}\text { The more knowledge a } \\
\text { person has about CAM, } \\
\text { the more likely he/she is } \\
\text { to use it }\end{array}$ & 3.3 & 66.5 \\
\hline $\begin{array}{l}\text { Peoples are more likely } \\
\text { to use CAM if his/her } \\
\text { friends or relative } \\
\text { discuss it with them }\end{array}$ & 3.8 & 76.0 \\
\hline $\begin{array}{l}\text { Peoples are more likely } \\
\text { to use CAM if his/her } \\
\text { teachers discuss it with } \\
\text { them }\end{array}$ & 3.8 & 75.2 \\
\hline $\begin{array}{l}\text { Believing on mental and } \\
\text { spiritual aspect of health } \\
\text { encourages the use of } \\
\text { CAM. }\end{array}$ & 3.7 & 73.7 \\
\hline
\end{tabular}

\section{CAM awareness and use by gender}

Table 5 shows a significant difference between the female and male students regarding the level of awareness of acupuncture, yoga, aromatherapy, and massage. The female students were more aware of CAM modalities when compared with the male students, as indicated by the odds ratios of (0.59), (0.47), (0.47), and (0.48) respectively. Gender differences were found significant in the self-use of CAM modalities like yoga, herbal medicine, massage, and prayers and spirituality. The percentage and odds ratios revealed that the female students were more likely to use these modalities, except for prayers and spirituality which were 1.648 times more likely to be used by the male students.

\section{CAM awareness and use by college}

Table 6 represents the results of the chi-square test for the association among the students of various colleges and the awareness or self-use of CAM modalities. Significant differences in regard to the awareness of acupuncture, yoga, and aromatherapy were found among the students of CON, COD, and COM with significantly higher percentages of $(75.9 \%)$, $(81.3 \%)$ and $(73.3 \%)$ respectively. No significant difference was observed in the selfuse of CAM modalities among the students of different colleges, except for acupuncture. The students of the CON (17.2\%) were more inclined to use acupuncture, followed by the students of the COSHP (11.4\%).

\section{CAM awareness and use by the level of study}

There was no observed significant association between the students' study levels and the awareness or use of CAM (Table 7). The only observed significant modality was acupuncture, which was more used by the students at their third level/ year of study $(11.5 \%)$. However, a tiny percentage of students used acupuncture.

\section{CAM awareness and use related to father's education}

The results related to the association between CAM awareness and use and the level of education of the respondent's father are summarized in Table 8 . The respondent's awareness of massage, acupuncture, and prayers and spirituality was significantly associated with their father's level of education. The respondents whose fathers had a university level of education were found to be more aware of CAM modalities, compared with other students, since significantly higher percentages of awareness of acupuncture (68.1\%), massage (84.6), and prayers (91.6) was found among them. The participants' use of massage (49.1\%) and nutritional supplements $(60.4 \%)$ were also found to be significantly associated with their fathers' higher education levels. The higher the father's education level, the more use of these modalities among the participants.

\section{Association of CAM awareness and use related to mother's education}

Table 9 summarizes the results of the respondents' awareness and use of CAM, related to their mothers' level of education. Significant differences were reported regarding the level of awareness of acupuncture (74.2\%), yoga $(73.9 \%)$, and massage $(86.5 \%)$ in the respondents whose mothers had higher levels of education. Furthermore, the use of acupuncture (19\%), yoga $(22.9 \%)$, and nutritional supplements $(58.6 \%)$ differed significantly among the respondents according to their mothers' level of education. The highest percentage of the use of acupuncture was found among the respondents whose mothers were 
illiterate. The highest percentages of yoga and nutritional supplements were $(22.9 \%)$ and (58.1 $\%$ ) respectively and were reported among the respondents whose mothers had university level of education.

\section{Awareness and use of CAM related to income}

The association between the respondents awareness and use of CAM modalities and their family income are shown in Table 10. The awareness of the two modalities; yoga and nutritional supplements, was significantly different among the respondents. The respondents whose families had higher incomes were more knowledgeable about CAM modalities, when compared with other students. The percentages of yoga and nutritional supplements were (74.2) and (89.9) respectively. A significant association was noted in the use of nutritional supplements and family income. The respondents whose families had high income were more likely $(62.7 \%)$ to use nutritional supplements, when compared with others.

\section{Association of awareness and use of CAM with having relatives in health professions}

Our data did not illustrate any significant association of the students' awareness and use of any CAM modalities and having any of their relatives in the health professions (Table 11).

\section{Beliefs and attitudes towards CAM related to gender and colleges}

Table 12 shows the participants' beliefs and attitudes towards CAM by gender. Between the male and female respondents, there was a significant difference that was found in regard to the following statements: "CAM providers give good information on maintaining a healthy lifestyle," "CAM involves natural plant formulae which are healthier than taking drugs given by medical doctors," and "the more knowledge a person has about CAM, the more likely they use it." The female respondents had higher means of Likert scale of $3.38,3.14$, and 3.57 out of 5 , compared with the male respondents. At the college level, a significant difference was found among the participants of various colleges in regard to the following statements: "CAM involves natural plant formulae which are healthier than taking drugs given by medical doctors," and "the more knowledge a person has about CAM, the more likely they use it." The CON students had the highest means of Likert scale of 3.75 out of 5 for both statements.

\section{Beliefs and attitudes towards CAM by students' level/year of college and family income}

Table 13 shows the students' beliefs and attitudes towards CAM by their levels of study at college and their families income. A significant difference in the respondents' beliefs and attitudes towards CAM was observed in their different levels/years at college in regard to the following three statements: "CAM providers give good information on maintaining a healthy lifestyle," "CAM involves natural plant formulae which are healthier than taking drugs given by medical doctors," and "the more knowledge a person has about CAM, the more likely they use it". The students in their third level of study had the highest Likert scale means of $3.45,3.04$, and 3.52 respectively, compared with others.

A significant opposite association was found in the beliefs and attitudes towards CAM related to family income in regard to the following statements: "CAM providers give good information on maintaining a healthy lifestyle," and "CAM involves natural plant formulae which are healthier than taking drugs given by medical doctors." This shows that families with lower income increases the beliefs and attitudes towards CAM. However, a mixed association was found between the family income and the statement: "The more knowledge a person has about CAM, the more likely they use it."

\section{DISCUSSION}

Humans have been using traditional and/or complementary medicine for centuries and their awareness and use are constantly increasing with time. It is the same in Saudi Arabia where traditional medicine (TM) has been used and sold in almost all the cities and villages for different types of ailments [5]. This study results showed that prayer/ spirituality is considered the most effective and least harmful modality by most of the participants, followed by nutritional supplements, massage, cupping, herbal medicine, yoga, and acupuncture. Aromatherapy was considered the least effective modality and acupuncture the most harmful modality.

In a previous study conducted at the Western region of Saudi Arabia, the same pattern was seen for prayers and massage use and effectiveness [6]. Other studies from Kuwait [9], Pakistan [10] and Syria [11] also indicated that the widely known CAM practices among students are prayers/ spirituality and massage. The data in this study also indicated that less than $20 \%$ of 
Table 5: The association of gender with awareness and use/practice of CAM modalities

\begin{tabular}{|c|c|c|c|c|c|c|c|c|c|c|c|c|}
\hline \multirow{2}{*}{ Modality } & \multicolumn{2}{|c|}{ Male\% } & \multicolumn{2}{|c|}{ Female \% } & \multicolumn{2}{|c|}{$P$ value } & \multicolumn{2}{|l|}{ OR } & \multicolumn{2}{|c|}{ OR Lower $95 \% \mathrm{Cl}$} & \multicolumn{2}{|c|}{ OR Upper 95\% Cl } \\
\hline & Awareness & Use & Awareness & Use & Awareness & Use & Awareness & Use & Awareness & Use & Awareness & Use \\
\hline Acupuncture & 59.5 & 5.8 & 71.2 & 10.8 & $0.020^{*}$ & 0.072 & 0.593 & 0.508 & 0.380 & 0.241 & 0.923 & 1.073 \\
\hline Yoga & 64.1 & 11.6 & 79.1 & 32.4 & $0.002^{* *}$ & $0.000^{* *}$ & 0.471 & 0.274 & 0.291 & 0.163 & 0.762 & 0.461 \\
\hline Cupping & 83.3 & 17.0 & 83.5 & 12.2 & 0.932 & 0.209 & 1.024 & 1.469 & 0.587 & 0.804 & 1.781 & 2.681 \\
\hline Aromatherapy & 21.6 & 3.5 & 36.7 & 5.8 & $0.001^{* *}$ & 0.283 & 0.476 & 0.590 & 0.302 & 0.222 & 0.750 & 1.654 \\
\hline Herbal medicine & 77.6 & 42.9 & 79.1 & 59.7 & 0.725 & $0.001^{* *}$ & 0.914 & 0.506 & 0.553 & 0.333 & 1.510 & 0.769 \\
\hline Massage & 77.6 & 39.8 & 87.7 & 56.8 & $0.013^{*}$ & $0.001^{* *}$ & 0.483 & 0.501 & 0.269 & 0.330 & 0.867 & 0.762 \\
\hline Nutritional supplement & 84.2 & 51.4 & 87.1 & 61.2 & 0.441 & 0.061 & 0.791 & 0.671 & 0.435 & 0.441 & 1.437 & 1.020 \\
\hline Prayers/spirituality & 91.1 & 80.3 & 86.3 & 71.2 & 0.138 & $0.040^{*}$ & 1.625 & 1.648 & 0.851 & 1.022 & 3.100 & 2.658 \\
\hline
\end{tabular}

OR; Odd Ratio; *significant at 5\%; **significant at 1\%

Table 6: The Association of colleges with the awareness and use/practice of CAM modalities

\begin{tabular}{|c|c|c|c|c|c|c|c|c|c|c|c|c|c|c|}
\hline \multirow[t]{2}{*}{ Modality } & \multicolumn{2}{|c|}{ COSHP } & \multicolumn{2}{|c|}{ COM } & \multicolumn{2}{|l|}{ COP } & \multicolumn{2}{|c|}{ CAMS } & \multicolumn{2}{|c|}{ CON } & \multicolumn{2}{|c|}{ COD } & \multicolumn{2}{|c|}{$P$-value } \\
\hline & Awareness & Use & Awareness & Use & Awareness & Use & Awareness & Use & Awareness & Use & Awareness & Use & Awareness & Use \\
\hline Acupuncture & 67.5 & 11.4 & 63.6 & 2.5 & 53.1 & 9.4 & 50.0 & 4.7 & 75.9 & 17.2 & 75.0 & 6.3 & $0.049^{*}$ & $0.039^{*}$ \\
\hline Yoga & 64.2 & 15.4 & 78.8 & 21.2 & 65.6 & 9.4 & 60.9 & 20.3 & 62.1 & 20.7 & 81.3 & 28.1 & $0.039^{\star}$ & 0.394 \\
\hline Cupping & 82.1 & 17.9 & 90.7 & 9.3 & 78.1 & 18.8 & 78.1 & 18.8 & 72.4 & 13.8 & 90.6 & 18.8 & 0.064 & 0.403 \\
\hline Aromatherapy & 19.5 & 6.5 & 73.3 & 2.5 & 40.6 & 9.4 & 18.8 & 3.1 & 13.8 & 3.4 & 31.3 & 0.0 & $0.003^{* *}$ & 0.227 \\
\hline Herbal medicine & 74.8 & 45.5 & 81.4 & 44.9 & 75.0 & 50.0 & 71.9 & 56.3 & 82.8 & 58.6 & 90.6 & 50.0 & 0.264 & 0.576 \\
\hline Massage & 78.0 & 43.9 & 84.7 & 44.9 & 87.5 & 53.1 & 75.0 & 46.9 & 86.2 & 51.7 & 81.3 & 40.6 & 0.456 & 0.765 \\
\hline $\begin{array}{l}\text { Nutritional } \\
\text { supplement }\end{array}$ & 80.5 & 50.4 & 88.1 & 58.5 & 87.5 & 50.0 & 85.9 & 57.8 & 82.8 & 51.7 & 90.6 & 59.4 & 0.548 & 0.774 \\
\hline Prayers/spirituality & 89.4 & 84.6 & 94.9 & 76.3 & 90.6 & 75.0 & 84.4 & 75.0 & 79.3 & 62.1 & 87.5 & 71.9 & 0.117 & 0.137 \\
\hline
\end{tabular}

*significant at 5\%; **significant at $1 \%$ 
Table 7: Association of the level of college with the awareness and use/practice of CAM modalities

\begin{tabular}{|c|c|c|c|c|c|c|c|c|c|c|}
\hline \multirow[t]{2}{*}{ Modality } & \multicolumn{2}{|c|}{ First } & \multicolumn{2}{|c|}{ Second } & \multicolumn{2}{|c|}{ Third } & \multicolumn{2}{|c|}{ Fourth } & \multicolumn{2}{|c|}{$p$ value } \\
\hline & Awareness & Use & Awareness & Use & Awareness & Use & Awareness & Use & Awareness & Use \\
\hline Acupuncture & 66.7 & 0.0 & 68.6 & 5.7 & 67.7 & 11.5 & 57.4 & 3.7 & 0.213 & $0.036^{*}$ \\
\hline Yoga & 66.7 & 11.1 & 68.6 & 17.1 & 66.1 & 17.2 & 73.5 & 21.6 & 0.522 & 0.666 \\
\hline Cupping & 100 & 11.1 & 82.9 & 11.4 & 80.7 & 16.7 & 86.4 & 14.8 & 0.274 & 0.842 \\
\hline Aromatherapy & 33.3 & 0.0 & 22.9 & 0.0 & 25.9 & 5.7 & 29.0 & 3.7 & 0.793 & 0.378 \\
\hline Herbal medicine & 77.8 & 55.6 & 74.3 & 51.4 & 80.2 & 48.8 & 76.5 & 48.1 & 0.795 & 0.960 \\
\hline Massage & 66.7 & 44.4 & 91.4 & 51.4 & 82.3 & 44.8 & 78.4 & 45.7 & 0.202 & 0.912 \\
\hline Nutritional supplement & 77.8 & 55.6 & 85.7 & 57.1 & 84.4 & 52.6 & 86.4 & 56.8 & 0.875 & 0.870 \\
\hline Prayers/spirituality & 77.8 & 77.8 & 88.6 & 68.6 & 90.6 & 81.8 & 88.9 & 73.5 & 0.645 & 0.169 \\
\hline
\end{tabular}

Table 8: Association of father's education with awareness and use of CAM modalities

\begin{tabular}{|c|c|c|c|c|c|c|c|c|c|c|}
\hline \multirow{2}{*}{ Modality } & \multicolumn{2}{|l|}{ None } & \multicolumn{2}{|c|}{ Primary } & \multicolumn{2}{|c|}{ Secondary } & \multicolumn{2}{|c|}{ University } & \multicolumn{2}{|c|}{$P$-value } \\
\hline & Awareness & Use & Awareness & Use & Awareness & Use & Awareness & Use & Awareness & Use \\
\hline Acupuncture & 60.0 & 0.0 & 44.0 & 4.0 & 54.2 & 8.4 & 68.1 & 7.7 & $0.020^{*}$ & 0.810 \\
\hline Yoga & 80.0 & 20.0 & 64.0 & 12.0 & 62.7 & 15.7 & 71.6 & 20.4 & 0.388 & 0.628 \\
\hline Cupping & 100 & 0.0 & 80.0 & 28.0 & 81.9 & 12.0 & 84.2 & 15.4 & 0.690 & 0.196 \\
\hline Aromatherapy & 20.0 & 0.0 & 24.0 & 8.0 & 24.1 & 3.6 & 28.1 & 4.2 & 0.859 & 0.762 \\
\hline Herbal medicine & 100 & 60.0 & 80.0 & 44.0 & 75.9 & 47.0 & 78.2 & 49.5 & 0.638 & 0.887 \\
\hline Massage & 40.0 & 0.0 & 72.0 & 44.0 & 74.7 & 37.3 & 84.6 & 49.1 & $0.01^{* *}$ & $0.048^{*}$ \\
\hline Nutritional supplement & 100 & 40.0 & 72.0 & 48.0 & 79.5 & 38.6 & 87.7 & 60.4 & $0.049^{*}$ & $0.004^{* *}$ \\
\hline Prayers/spirituality & 60.0 & 60.0 & 80.0 & 68.0 & 86.7 & 75.9 & 91.6 & 78.6 & $0.030^{*}$ & 0.488 \\
\hline
\end{tabular}

*significant at 5\%; **significant at 1\%

Table 9: Association of mother's education with awareness and use of CAM modalities

\begin{tabular}{|c|c|c|c|c|c|c|c|c|c|c|}
\hline \multirow[b]{2}{*}{ Modality } & \multicolumn{2}{|c|}{ None } & \multicolumn{2}{|c|}{ Primary } & \multicolumn{2}{|c|}{ Secondary } & \multicolumn{2}{|c|}{ University } & \multicolumn{2}{|c|}{$p$ value } \\
\hline & Awareness & Use & Awareness & Use & $\begin{array}{l}\text { Awarenes } \\
s\end{array}$ & Use & $\begin{array}{l}\text { Awarenes } \\
s\end{array}$ & Use & Awareness & Use \\
\hline Acupuncture & 52.4 & 19.0 & 40.0 & 11.4 & 74.2 & 7.9 & 64.0 & 5.9 & $0.003^{* *}$ & $0.025^{*}$ \\
\hline Yoga & 38.1 & 9.5 & 45.7 & 14.3 & 73.0 & 11.2 & 73.9 & 22.9 & $0.000^{* *}$ & $0.039^{*}$ \\
\hline Cupping & 81.0 & 19.0 & 77.1 & 11.4 & 85.4 & 16.9 & 84.2 & 15.0 & 0.694 & 0.847 \\
\hline Aromatherapy & 9.5 & 0.0 & 25.7 & 11.4 & 28.1 & 5.6 & 28.1 & 3.2 & 0.322 & 0.091 \\
\hline Herbal medicine & 81.0 & 33.3 & 74.4 & 60.0 & 77.5 & 49.4 & 79.1 & 48.2 & 0.762 & 0.282 \\
\hline Massage & 61.9 & 28.6 & 57.1 & 40.0 & 86.5 & 49.4 & 84.2 & 46.6 & $0.000^{* *}$ & 0.317 \\
\hline Nutritional supplement & 85.7 & 33.3 & 71.4 & 48.6 & 84.3 & 52.8 & 87.4 & 58.1 & 0.100 & $0.022^{*}$ \\
\hline Prayers/spirituality & 85.7 & 61.9 & 80.0 & 74.3 & 93.3 & 82.0 & 89.7 & 77.1 & 0.171 & 0.248 \\
\hline
\end{tabular}

${ }^{\star *}$ significant at 1\%; *significant at 5\% 
Khan et al

Table 10: Association of family income with awareness and use of CAM modalities

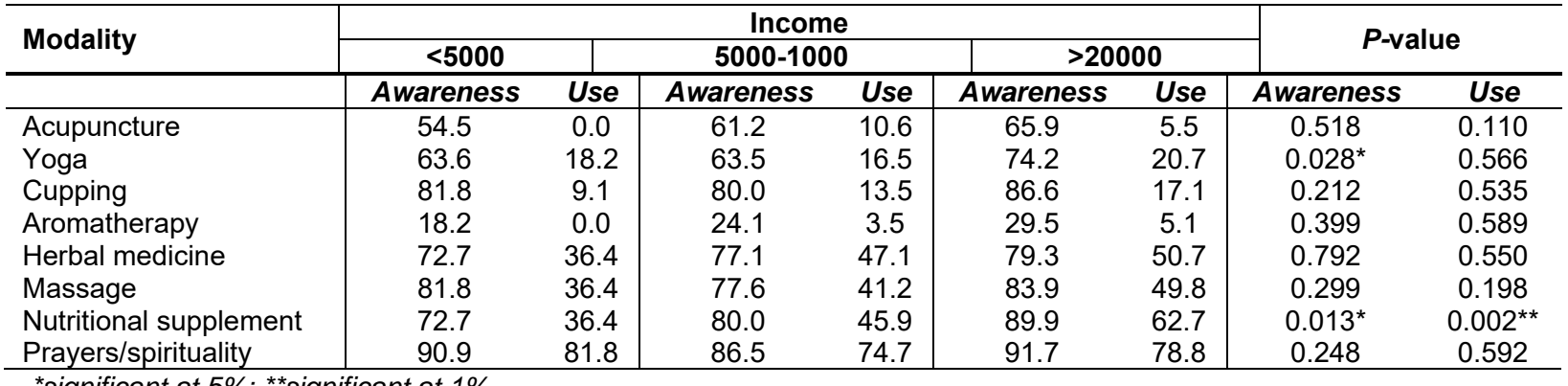

*significant at 5\%; **significant at 1\%

Table 11: The association of awareness and use of CAM modalities with students' relatives in health profession

\begin{tabular}{l|cc|c|cc|cc|cc}
\hline Modality & \multicolumn{2}{|c|}{$\boldsymbol{P}$-value } & OR & \multicolumn{2}{c|}{ OR Lower 95\% Cl } & \multicolumn{3}{c}{ OR Upper 95\% Cl } \\
\hline & & Awareness & Use & Awareness & Use & Awareness & Use & Awareness & Use \\
\hline Acupuncture & 0.900 & 0.133 & 0.974 & 0.551 & 0.647 & 0.251 & 1.467 & 1.210 \\
Yoga & 0.213 & 0.420 & 1.314 & 1.230 & 0.854 & 0.744 & 2.020 & 2.033 \\
Cupping & 0.831 & 0.973 & 0.944 & 0.973 & 0.554 & 0.563 & 1.607 & 1.681 \\
Aromatherapy & 0.775 & 0.294 & 1.067 & 1.682 & 0.685 & 0.627 & 1.663 & 4.511 \\
Herbal medicine & 0.186 & 0.241 & 1.384 & 0.779 & 0.854 & 0.525 & 2.243 & 1.156 \\
Massage & 0.132 & 0.468 & 1.482 & 0.864 & 0.887 & 0.581 & 2.476 & 1.283 \\
Nutritional supplement & 0.687 & 0.122 & 1.121 & 1.368 & 0.643 & 0.920 & 1.956 & 2.036 \\
Prayers/spirituality & 0.139 & 0.132 & 1.645 & 1.441 & 0.846 & 0.895 & 3.198 & 2.319 \\
\hline
\end{tabular}


Table 12: Likert scale mean values of the response of students' beliefs and attitude towards CAM based on gender and college

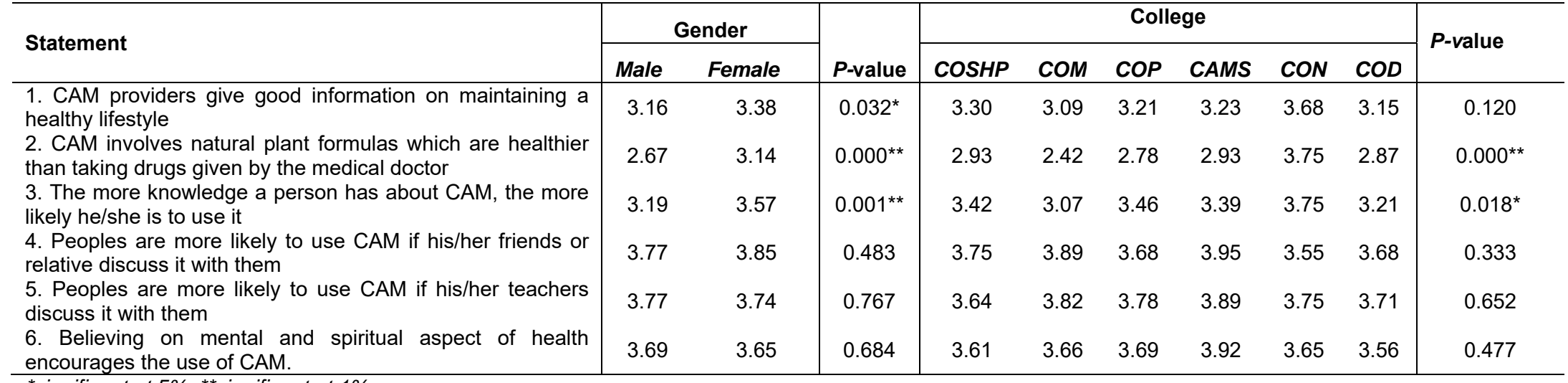

encourages the use of CAM.

Table 13: Likert scale mean values of the students' beliefs and attitude towards CAM based on year/level in college and family income

\begin{tabular}{|c|c|c|c|c|c|c|c|c|c|}
\hline \multirow[b]{2}{*}{ Statement } & \multicolumn{4}{|c|}{ Level/year in college } & \multirow[b]{2}{*}{$P$-value } & \multicolumn{3}{|c|}{ Family Income } & \multirow[b]{2}{*}{$P$-value } \\
\hline & First & Second & Third & Fourth & & $<5000$ & $\begin{array}{l}5000- \\
1000\end{array}$ & $>10000$ & \\
\hline $\begin{array}{l}\text { 1. CAM providers give good information on } \\
\text { maintaining a healthy lifestyle }\end{array}$ & 2.55 & 3.11 & 3.45 & 3.04 & $0.000^{* *}$ & 3.54 & 3.45 & 3.03 & $0.000^{* *}$ \\
\hline $\begin{array}{l}\text { 2. CAM involves natural plant formulas which are } \\
\text { healthier than taking drugs given by the medical doctor }\end{array}$ & 2.66 & 2.71 & 3.04 & 2.59 & $0.007^{* *}$ & 2.72 & 3.12 & 2.59 & $0.000^{* *}$ \\
\hline $\begin{array}{l}\text { 3. The more knowledge a person has about CAM, the } \\
\text { more likely he/she is to use it }\end{array}$ & 3.00 & 3.34 & 3.52 & 3.13 & $0.002^{* \star}$ & 3.00 & 3.53 & 3.17 & $0.003^{* *}$ \\
\hline $\begin{array}{l}\text { 4. Peoples are more likely to use CAM if his/her } \\
\text { friends or relative discuss it with them }\end{array}$ & 4.22 & 3.68 & 3.82 & 3.77 & 0.492 & 3.45 & 3.78 & 3.83 & 0.436 \\
\hline $\begin{array}{l}\text { 5. Peoples are more likely to use CAM if his/her } \\
\text { teachers discuss it with them }\end{array}$ & 4.11 & 3.68 & 3.78 & 3.73 & 0.685 & 4.00 & 3.76 & 3.74 & 0.714 \\
\hline $\begin{array}{l}\text { 6. Believing on mental and spiritual aspect of health } \\
\text { encourages the use of CAM. }\end{array}$ & 3.88 & 3.45 & 3.72 & 3.67 & 0.503 & 3.27 & 3.71 & 3.68 & 0.939 \\
\hline
\end{tabular}

${ }^{* *}$ significant at $1 \%$ 
the participants used acupuncture, yoga and cupping. Nevertheless, most participants were aware of these modalities and more than half of them (56-65 \%) consider these modalities effective but may lead to some degree of toxicity. This high level of awareness, use and perception of the effectiveness of spirituality/prayers, massage and cupping may be due to the association of cultural and religious standards which are more commonly practiced by the family members of the respondents in this region. Such beliefs about the efficacy and safety of these CAM practices are transferred to their descendants by sharing personal experiences and taking their children to practicing professionals [10].

Most of the respondents chose relatives/friends as source of information about CAM, followed by the media, other health professionals, CAM practitioners and books. On the other hand, the least information was obtained from formal CAM trainings/courses. This indicates the unavailability of formal trainings and courses in the academic institutions. Therefore, most participants think that the lack of knowledge, scientific evidence, trained professionals on CAM and long-time of treatment could be barriers to the use and implementation of CAM. Examining the widespread awareness and use of CAM in Saudi Arabia, the Saudi Ministry of Health established a center for CAM. This followed the ministerial decree No. 236 dated 10/8/1429 H $(12 / 8 / 2008 \mathrm{AD})$ issued to regulate CAM practices within the health-care services and use Evidence-Based CAM to complement the conventional medicine [12].

The association of awareness and self-use of CAM related to gender, colleges, level/year of study, educational status of parents, family income, and presence of the participants' friends/relatives in the health sector indicated some interesting results. In regard to the sources of information about CAM, the data showed that the participants obtained more information from their friends/relatives and media. This indicates the impact of family, culture and media as a source of information [13]. The findings of this study are consistent with similar previous studies conducted in the Western region [6] and Majmaah province [14] of Saudi Arabia.

Many Evidence-Based studies from different parts of the world, like Malaysia, Pakistan, Saudi Arabia, and the United States demonstrate positive attitudes and beliefs towards CAM practices [10,14-16]. The results of this study also showed the same pattern that the majority of participants have a perception that general CAM modalities and practitioners provide useful information about keeping a healthy lifestyle. They also support the use of CAM for the spiritual and mental aspects of health. Nonetheless, the participants believe that they will probably use CAM if CAM health professionals and teachers provide them with more knowledge and information. This reflects the significance of CAM for health professionals. Thus, restructuring the formal courses about CAM in the curricula would help the public in both the use and the misuse matters of CAM. Consequently, this highlights the necessity to review the academic curricula and health policies. This is to regulate and standardize CAM healthcare practices to ensure protecting the public [10].

This study has observed significant differences $(p<0.05)$ among gender, colleges, fathers/mothers' education level, family income awareness, and use of some CAM modalities. The female participants' awareness of acupuncture, yoga, aromatherapy, and massage was significantly higher than the male participants. Awareness of CAM modalities was higher among the students of medical colleges. However, the use of CAM modalities among the students of Medicine was lower than the students of other colleges, excluding spirituality/prayer and nutritional supplements. This could be due to the inadequate information about the risks and benefits of CAM [17].

The study results did not find any significant association among the different levels of the students at colleges, the presence of relatives in healthcare professions and the awareness/selfuse of most CAM modalities. Hence, this may be due to the differences in the socioeconomic backgrounds and the available sources of knowledge provided to the students [18].

The data indicated that the students in general have positive beliefs and attitudes towards most CAM modalities. Most of the students believe that the spiritual and mental aspects of health encourage them to use CAM. Additionally, they opined that they will probably use CAM if their relatives and/or teachers discuss it with them. Furthermore, the data in this study indicate that the female students, in a significantly higher number, have a positive attitude towards the use and safety of CAM. Similarly, this belief and attitude increased in regard to the students' level/grade, the college and, to some extent, the family income.

To the best of our knowledge, this study is one of the pioneer studies about investigating the 
awareness, perception, self-use, attitude and beliefs towards different CAM modalities among the students of six health professions colleges (COM, COP, COD, CON, COAMS, and COSHP) in the Central region of Saudi Arabia. An appropriate sample size and a validated questionnaire were used. This study focused on the association between the students' demographic characteristics and their awareness and self-use of the different modalities of CAM. In addition, this study included a comparison of all COM modalities between the Central and Western Regions of Saudi Arabia.

\section{Limitations of the study}

This is a cross-sectional study. Therefore, the factors that affect the students' responses cannot be studied over a long period of time because the students' knowledge and attitudes may change with time, as shown in previous studies [10]. Hence, a panel study should be conducted to further explain these behaviors.

\section{CONCLUSION}

Formal courses and trainings on CAM should be added to the curricula of healthcare students. This will help fill the gaps in their knowledge of CAM and will enable them to acquire the essential tools to meet the needs and expectations of their patients regarding use of CAM.

\section{DECLARATIONS}

\section{Acknowledgement}

We highly appreciate the cooperation of students, faculty, administration of King Saud bin Abdulaziz University for Health Sciences Riyadh for their support and help in the collection of data.

\section{Conflict of interest}

No conflict of interest is associated with this study.

\section{Author's contribution}

We declare that this work was done by the authors named in this article and all liabilities pertaining to claims relating to the content of this article will be borne by the authors. AK; Designed and supervised the study, wrote the first draft of the manuscript, MEA; Statistically analyzed the data and wrote the results section. AA, AAS, SFZ; Helped in study design, data entry and manuscript revision. IM, ZF, DSR; Collected data form students, helped in research proposal writing and manuscript revision. All authors have read and approved the final form of the manuscript.

\section{Open Access}

This is an Open Access article that uses a funding model which does not charge readers or their institutions for access and distributed under the terms of the Creative Commons Attribution License (http://creativecommons.org/licenses/by/ 4.0) and the Budapest Open Access Initiative (http://www.budapestopenaccessinitiative.org/rea d), which permit unrestricted use, distribution, and reproduction in any medium, provided the original work is properly credited.

\section{REFERENCES}

1. World Health Organization: WHO Traditional Medicine Strategy 2002-2005. World Health Organization Geneva, Switzerland. 2002.

2. Hans M, Martin F Study of Holarrhena congolensis Stapf. from the Gimbi region of the Belgian Congo. J Pharm Belg. 1954; 9: 391-402.

3. National Center for Complementary and Integrative Health. "Complementary, alternative, or integrative health: what's in a name?" US Department of Health and Human Services, National Institutes of Health. 2015.

4. Waddington $F$, Lee J, Naunton $M$, Kyle $G$, Thomas J, O'Kane G. Complementary medicine use among Australian patients in an acute hospital setting: an exploratory, cross sectional study. BMC Complement Altern Med. 2019; 19:1-7.

5. Organization WH: Legal status of traditional medicine and complementary. Geneva: World Health Organization. 2001;81-82.

https://apps.who.int/medicinedocs/pdf/h2943e/h2943e.p $d f$

6. Khan A, Ahmed ME, Aldarmahi A, Zaidi SF, Subahi AM, Al Shaikh A, Alghamdy Z, Alhakami LA: Awareness, Self-Use, Perceptions, Beliefs, and Attitudes toward Complementary and Alternative Medicines (CAM) among Health Professional Students in King Saud bin Abdulaziz University for Health Sciences Jeddah, Saudi Arabia. Evid Based Complement Alternat Med. 2020.

7. Council for International Organizations of Medical Sciences, International ethical guidelines for healthrelated research involving humans. World Health Organization. 2017.

8. Cochran WG: Sampling techniques. John Wiley \& Sons, New York, USA. 1977.

9. Awad A, Al-Ajmi S, Waheedi M. Knowledge, perceptions and attitudes toward complementary and alternative 
therapies among Kuwaiti medical and pharmacy students. Med Princ Pract. 2012; 21: 350-354.

10. Ashraf $M$, Saeed $H$, Saleem Z, Rathore $H A$, Rasool $F$, Tahir E, Bhatti T, Khalid J, Bhatti I, Tariq A. A crosssectional assessment of knowledge, attitudes and selfperceived effectiveness of complementary and alternative medicine among pharmacy and nonpharmacy university students. BMC Complement Altern Med. 2019; 19: 95.

11. James $P B$, Bah AJ: Awareness, use, attitude and perceived need for Complementary and Alternative Medicine (CAM) education among undergraduate pharmacy students in Sierra Leone: a descriptive crosssectional survey. BMC Complement Altern Med. 2014, 14:438.

12. Alrowais NA, Alyousefi NA. The prevalence extent of Complementary and Alternative Medicine (CAM) use among Saudis. Saudi Pharm J. 2017; 25: 306-318.

13. Lee G, Charn $\mathrm{T}$, Chew Z, Ng T. Complementary and alternative medicine use in patients with chronic diseases in primary care is associated with perceived quality of care and cultural beliefs. Family practice. 2004; 21: 654-660.

14. Al Mansour MA, Al-Bedah AM, AlRukban MO, Elsubai IS, Mohamed EY, El Olemy AT, Khalil AA, Khalil MK,
Alqaed MS, Almudaiheem A. Medical students' knowledge, attitude, and practice of complementary and alternative medicine: a pre-and post-exposure survey in Majmaah University, Saudi Arabia. Adv Med Educ Pract. 2015; 6: 407.

15. Jamshed SQ, Khan MU, Ahmad A, Elkalmi RM. Knowledge, perceptions, and attitudes toward complementary and alternative medicines among pharmacy students of a Malaysian Public University. $\mathrm{J}$ Pharm Bioallied Sci 2016, 8: 34.

16. Kanadiya MK, Klein G, Shubrook JH. Use of and attitudes toward complementary and alternative medicine among osteopathic medical students. J Am Osteopath Assoc. 2012; 112: 437-446.

17. Schnabel $K$, Binting $S$, Witt $C M$, Teut $M$. Use of complementary and alternative medicine by older adults--a cross-sectional survey. BMC Geriatr. 2014; 14: 38.

18. Samara AM, Barabra ER, Quzaih HN, Zyoud SH. Use and acceptance of complementary and alternative medicine among medical students: a cross sectional study from Palestine. BMC Complement Altern Med. 2019; 19: 78. 